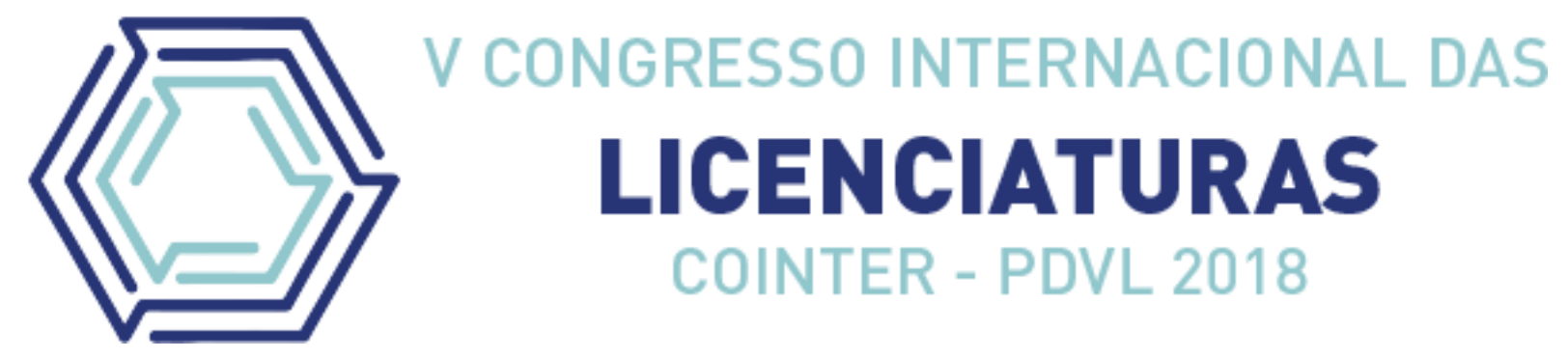

\title{
INTEGRALIZANDO EIXOS DE ENSINO: LEITURA, PRODUÇÃO TEXTUAL E ORALIDADE
}

\author{
Laécio Eugênio da Silva ${ }^{1}$; Niege da Rocha Guedes ${ }^{2}$ \\ DOI: https://doi.org/10.31692/2358-9728.VCOINTERPDVL.2018.00214
}

\section{Introdução}

O presente trabalho foi desenvolvido na disciplina de estágio em Língua Portuguesa II, ministrada pela docente Niege da Rocha Guedes no segundo semestre de 2017 na Universidade Federal Rural de Pernambuco - Unidade Acadêmica de Garanhuns (UFRPE-UAG). A finalidade era observar e reger aulas em uma turma do segundo ano do ensino médio, esse ensino aconteceu por meio do uso do gênero literário poema, que segundo Schneuwly e Dolz (2004) pode servir de instrumento para o ensino de línguas e também da integralização de eixos defendida por Marcuschi (2001), sendo eles: a leitura, a produção textual e a oralidade. Se concluiu que o uso do poema e dos eixos de formas integrada, contribuem para o desenvolvimento das habilidades e capacidades de linguagem.

\section{Fundamentação Teórica}

Segundo Schneuwly e Dolz (2004 ), antes, o texto era usado como objeto de uso, mas agora o gênero textual pode ajudar no ensino de línguas, possibilitando que o aluno desenvolva capacidades que se relacionam com o gênero em questão e habilidades que são trabalhadas através dos eixos de ensino escolhidos Ou seja, o texto passa a ser caracterizado como instrumento. Já Marcuschi (2001) defende a integralização ao se trabalhar os eixos, dizendo

\footnotetext{
${ }^{1}$ Curso: Licenciatura em Letras - Português, Inglês e suas literaturas. Instituição: Universidade Federal Rural de Pernambuco - Unidade Acadêmica de Garanhuns (UFRPE - UAG). E-mail: laecio.eugenio @ hotmail.com.

2 Titulação: Doutoranda em Ciências da Linguagem. Instituição: Universidade Federal Rural de Pernambuco - Unidade Acadêmica de Garanhuns (UFRPE - UAG). E-mail: nrguedes@uol.com.br
} 
que “...deve-se frisar que não se trata de transformar a fala num tipo de conteúdo autônomo no ensino de língua: ela tem de ser vista integradamente e na relação com a escrita." O autor acaba apontando a importância de se estudar os eixos de forma integrada. Nesse caso, a oralidade, que geralmente é esquecida, e a escrita. Mas por que não trazer a leitura para junto com eles também? Esses três pontos, quando trabalhados juntos, acabam ampliando as possibilidades de desenvolvimento do aluno na sala de aula.

\section{Metodologia}

O estudo em questão consiste em uma pesquisa de campo com caráter qualitativo. As observações e regências ocorreram no período de oito semanas em uma turma do segundo ano do ensino médio em uma Escola de Aplicação da cidade de Garanhuns - PE, totalizando 24 horas/aulas observadas/regidas. O método utilizado foi o da Observação do tipo participante, ou seja, com minha participação direta na coleta dos dados. Por fim, na prática em sala, foram trabalhados os eixos já citados, de forma integralizada, tendo o gênero literário poema como o instrumento desse ensino.

\section{Resultados e Discussões}

\section{- Observações}

Durante as observações, se constatou que a leitura foi trabalhada pelo professor através de poemas, partindo de escolas literárias como o naturalismo, romantismo e realismo. Fazer uso do texto literário para aperfeiçoamento das competências de leitura, mostra que o ensino vem mudando com o passar dos anos, como apontam Dolz \& Schneuwly (2004), quando dizem que o texto, que antes era tomado apenas como objeto de uso, agora passa a ser usado como suporte para o desenvolvimento de estratégias e habilidades de leitura na sala de aula. Sendo assim, mesmo que a passos curtos, podemos perceber que o ensino, pelo menos nesse ponto, vem mudando. Trabalhar leitura não é algo simples como pode parecer, muitos professores acham que pedindo para os alunos fazerem uma leitura superficial, já estão fazendo o suficiente; no entanto, ler um texto é mais que isso, é necessário haver uma reflexão, uma discussão acerca do assunto que o texto traz. Dessa forma, o discente não iria achar que está lendo por ler; agora, ao ler, ele se concentraria em focar nos aspectos trazidos pelo texto. 
Em relação à produção textual, se foi trabalhada, majoritariamente, através do projeto "Café literário", feito pelo professor de língua portuguesa, juntamente com a professora de Arte. Depois de algumas aulas explicando as características do gênero literário poema, foi pedido ao aluno que produzisse algo que mostrasse a "liberdade de expressão", alguns alunos trouxeram desenho, outros músicas, e teve gente até que dançou, mas a grande maioria trouxe poesias de própria autoria. Mesmo com a questão da liberdade poética sabemos que existe alguns limites não só para o poema, mas para todos os gêneros textuais de uma forma geral. Os estudantes escreveram seus poemas de forma que a estrutura respeitava a licença poética.

A oralidade se foi observada também através do projeto, no momento em que os alunos tiveram que expor seus poemas para a turma. Foi um momento muito interessante, pois além de oralizarem suas poesias, os alunos também falavam o que os motivou a escrever. Para Belintane (2016) integrante do GOLE (Grupo Oralidade, Leitura e Escrita) criado há mais de uma década, “...a performance é o elemento que marca a oralidade, pois, na essência, estamos nos referindo ao processo de memorizar, retextualizar, declamar, narrar, apresentar, formular, reformular etc., mas tudo de memória, apostando na estética do texto e da performance.”. Sendo assim, a oralidade acontece através da expressão, quando há uma exploração do estilo do gênero e da camada estética do texto oral e isso a turma observada fez muito bem.

\section{- Regências}

Devido à divergência de calendários entre a escola e a universidade, ocasionando a falta de tempo, a regência ocorreu de forma alternada com as observações, visando o projeto "Café literário". O tempo foi curto, mas foi o suficiente para focar nos eixos da leitura, da produção textual e da oralidade.

O projeto se dividiu em três etapas, a primeira foi a da leitura, na qual foram trazidos alguns poemas para serem lidos com a turma; apesar do professor também ter trazido, eu quis reforçar. Foram discutidas as características do poema, estrutura, ritmo, etc. Essa etapa foi de extrema importância para a segunda etapa.

Na segunda etapa, o foco foi a produção textual, pois, como já havíamos discutido as características do gênero, os alunos tinham uma boa noção de como escrever. Alguns dos discentes já tinham seus poemas prontos; com esses, foi trabalhado o processo de revisão do texto, questões como a estrutura e ritmo foram observadas de forma mais atenta. Quando todos estavam com seus poemas, foram feitas algumas colocações e os alunos tiveram a oportunidade 
de reescreverem seus textos. Tanto o processo de revisão quanto o de reescrita são de extrema importância para se ter um bom texto como resultado final. No livro Produção escrita e dificuldades de aprendizagem, Dolz, Gagnon \& Decândio (2010) apontam a necessidade de se utilizar dessas estratégias para se produzir algo escrito.

Como já apontei acima, a oralidade se foi muito bem trabalhada, a declamação dos textos pelos alunos ocorreu com êxito. Isso nos mostra que, apesar de ainda ser raro vermos a oralidade em sala de aula, está aparecendo aos poucos. Espera-se que, com o passar dos anos, ela vá ganhando cada vez mais espaço, e fique lado a lado com a escrita.

\section{Conclusões}

Trabalhos desse tipo, nos possibilitaram enxergar de forma diferente a relação teoriaprática, fazendo-nos refletir sobre quais estratégias usaremos quando estivermos exercendo a profissão. Além disso, a experiência em sala de aula, nos faz amadurecer como educadores; assim, quando realmente formos dar aula, já estaremos mais habituados ao ambiente.

Em síntese, levar para a sala de aula o gênero literário poema com o foco de se trabalhar leitura, produção textual e oralidade, contribui para o desenvolvimento das capacidades de linguagem dos alunos que estão atreladas aos três eixos trabalhados e ao gênero em questão. Além de também, possibilitar para os mesmos a oportunidade de conhecerem mais afundo o poema, que muitas vezes é usado apenas como objeto de uso para se trabalhar conteúdos gramaticais.

\section{Referências}

BELINTANE, Claudemir. et al. GOLE (Grupo Oralidade, Leitura e Escrita). Disponível em: <https://www.grupo-oralidade-leitura-escrita.com/oralidade>. Acesso em 03 de Agosto de 2017.

DOLZ, Joaquim; DECÂNDIO, Fabrício; GAGNON, Roxane. Produção escrita e dificuldades de aprendizagem. Campinas: Mercado de Letras, 2010.

MARCUSCHI, Luiz. A. Oralidade e ensino de língua: uma questão pouco "falada". In: DIONISIO, A. P. \& BEZERRA, M. A. (Orgs). O livro didático de Português: múltiplos olhares. Rio de Janeiro: Lucerna, 2001. p. 19-32.

SCHENEUWELY, Bernard; DOLZ, Joaquim; Gêneros orais e escritos na escola. Campinas: 
Mercado de Letras, 2004. 